\title{
Experiência com graffitis: modos de resistência e educação informal
}

\author{
Paulo Roberto Faber Tavares Junior ${ }^{1}$ \\ Alberto D'Avila Coelho ${ }^{2}$
}

\begin{abstract}
Resumo
Este artigo trata de experiências com graffitis tendo a rua como "sala" de aula. Pergunta-se: como os graffitis favorecem outros modos de aprender, problematizando a estrutura escolar formalizada? O referencial teórico se apoia em conceitos como resistência, aprender e vontade de potência. Com o método de pesquisa cartográfico tem-se uma abordagem que busca escapar a explicações determinantes, possibilitando perceber os graffitis em sua condição estética e política, favorecendo um tipo de aprender conectado com as forças que movimentam a vida cotidiana. Com ou sem autorização os graffitis ocupam as ruas, são modos de estar no mundo que buscam resistir a assujeitamentos. Palavras-chave: Graffiti; Modos de Resistência; Educação Informal.
\end{abstract}

\section{Experiences with graffitis: forms of resistance and informal education}

\section{Abstract}

This article deals with experiences with graffitis taking the streets as the "classroom ". We ask: how do graffitis favor other forms of learning questioning the structure formal school? Theorical reference is based on concepts such as resistance, learning and potential willingness. With the cartographic research methodology we present an approach that attempts to escape from determinant explanations, allowing us to perceive the graffitis in their aesthetics and political conditions, favoring a kind of learning connected to the forces that move daily life. Authorized or not, graffitis fill the streets and are forms of being in the world that aim to resist to subjection.

Keywords: Graffiti; Forms of Resistance; Informal Education.

\section{Experiencia con graffitis: modos de resistencia y educación informal}

\section{Resumen}

Este artículo trata de experiencias con graffitis teniendo la calle como "aula" de clase. Se pregunta: ¿cómo los graffitis favorecen otros modos de aprender, problematizando la estructura escolar formalizada? El referencial teórico se apoya en los conceptos de resistencia, aprender y voluntad de potencia. Con el método de investigación cartográfico se tiene un enfoque que busca escapar a explicaciones determinantes, posibilitando percibir los graffitis en su condición estética y política, a favorecer un tipo de aprendizaje conectado a las fuerzas que mueven la vida cotidiana. Con o sin autorización los graffitis ocupan las calles, son modos de estar en el mundo que buscan resisten a los sometimientos. Palabras clave: Graffiti; Modos de Resistencia; Educación Informal.

\section{Introdução}

Viver a rua, acessar o quantum experimental e poético que, de modo fugaz, se produz por instantes nas suas intersecções sensíveis. Ativar corpos, corpos que devido aos modos

\footnotetext{
${ }^{1}$ Doutorando Universidade Federal do Rio Grande do Sul, Porto Alegre/ RS, paulofaber@gmail.com ${ }^{2}$ Prof. Dr. Instituto Federal Sul-rio-grandense (IFSUL), Pelotas/ RS, albercoelho@terra.com.br
} 
formatadores, operantes na atualidade, muitas vezes vegetam inativos. Produzimos saberes a partir das intervenções com o corpo da cidade, partindo das inscrições urbanas como os graffitis, práticas promotoras de experiências estéticas no espaço urbano, em meio aos "gritos" públicos que tentam quebrar o gesso de uma contemporaneidade privada, trancafiada em modelos. Inscrições urbanas, intervenções gráfico-visuais presentes pelo espaço urbano, os graffitis são intervenções artísticas que tem no espaço urbano sua matéria de criação.

Colocada como espaço da marginalidade, a rua é muitas vezes demonizada. Um submundo. A rua é penalizada por uma cultura que marginaliza os espaços para que se possam criar áreas delimitadas, vendidas como seguras e intermediadas por consumo e padronizações. Cultura que transforma tudo em capital, em monetização e consumo. Vende-se segurança, entregue em forma de isolamento e aprisionamento, "parecem estar em jogo aí enunciados muito semelhantes aos que motivaram as instituições disciplinares, porém, agora, ao invés de isolar o outro, usa-se outra estratégia: ilhar-se." (COSTA; MIZOGUCHI; FONSECA, 2004, p.175). Trocam-se praças e parques públicos por shopping centers e grandes condomínios, muitas vezes mesclados. Espaços padronizados em que figuram grandes marcas, redes de franquias que conseguem padronizar o que se come, o que se veste e o que se pensa; "o cidadão faz seu esquadrinhamento e frequenta tais locais onde a população é economicamente homogeneizada e onde acredita estar mais seguro" (COSTA; MIZOGUCHI; FONSECA, 2004, p.175). Vende-se o estilo de vida do momento, o desejo de tê-lo, a ideia de uma essência que se torna aprisionamento. Os espaços públicos ficam sujeitos a diversos tipos de controle, das câmeras de monitoramento aos modos de subjetivação, capazes de fazer o sujeito se autocontrolar. Na Sociedade de Controle segundo os estudos de Gilles Deleuze (1992), rarefeito, o controle passa a estar em toda parte. Com tanta segurança eliminam-se as multiplicidades, as possibilidades de novas singularidades.

O olho do "grande irmão", como disse George Orwell (2005), está em toda parte, tornando difícil escapar de representações, escapar de sermos algo para além do esperado, de não conferir o papel que nos é delegado. Sim, seguimos uma "trajetória sócio-profissional prédeterminada" (GUATTARI, 1992, p.178) como nos alerta Felix Guattari (1992), mas, se novas formas de controle são inventadas a cada dia, novas formas de "resistência" (DELEUZE, 1988, 1992, 1999) também devem surgir. 
Este artigo nasce de um projeto de investigação em educação junto ao espaço urbano, corpo em mutação no qual se ergue formas de resistência. Resistir, criar novos modos de existência e novas formas de vida que escapam às formatações. Resistir aos mais variados modos de produção de subjetividade, para favorecer singularidades e colocar as variáveis em estado de variação contínua.

Sem especificar nem celebrar aspectos técnicos de suas composições, a escrita trazida aqui chega por um olhar atento aos processos subjetivos promovidos pelas experiências com graffitis. Não se trata de "o que são" os graffitis, mas de "qual seu modo de funcionamento", do que eles podem ou do que nós podemos com eles. Temos como objetivos problematizar a experiência com alguns graffitis quanto à capacidade de produzir determinadas subjetividades, resistindo àquelas que agem na direção da reprodução e da afirmação de uma estrutura estabelecida e oficializada. E, destacar os modos de subjetivação que favorecem forças inventivas capazes de produzirem rupturas, destacando alguns graffitis que colaborem para uma educação potencializadora capaz de ensinar segundo princípios de informalidade e pautado pela capacidade intensificadora da "vontade de potência" dos indivíduos.

Utilizado em pesquisas de campo voltadas para o estudo da subjetividade, escolhemos o método cartográfico para esta ação, com ele buscamos compartilhar experiências que escapassem de uma abordagem explicativa e determinista, dando vasão ao trânsito pelas ruas da cidade de Pelotas/ RS. Dentre os motivos dessa escolha pela cartografia, dois se destacam: a orientação da linha de pesquisa com a qual a investigação esteve envolvida e o amálgama com o movimento urbano que ela faz. Pois se tem as ruas como um campo problemático, sendo mapa, território de passagem e implicação geográfica; é de onde se retira a matéria que dá consistência ao que se escreve. A cartografia é tomada junto ao aprendizado com a cidade muros, casas, edifícios, ruas, praças, pessoas, animais, graffitis, sonoridades, cheiros, caminhadas - tudo constituindo um território que permite colocar os corpos em deslocamentos.

Dentro do projeto de pesquisa, o processo cartográfico produziu registros a partir de entrevistas com inscritores urbanos, artistas "marginais", e participação em oficinas de graffitistencil-lambe-e-cia. Destaca-se também o acompanhamento de pichadores, quando em saída de campo, eventuais "rolés" marcados por uma experimentação de adrenalina na ação que envolve o corpo empírico, como prática de guerrilha para e com a cidade. 
Queremos aqui compartilhar experiências que nos permitiram acessar fluxos capazes de criar, modificar ou destruir mundos, num sentido nietzschiano, em que tais ações abram caminhos para o novo, para a realização de um grau de elevação da potência.

Para evidenciar que há no graffiti algo capaz de produzir sentido para um "estar-nacidade", utilizamos o conceito de "diferença". Trata-se de um modo de pensar, ou seja, é um exercício do pensamento que produz multiplicidades, no sentido da capacidade de se multiplicar, criar movimentos, devires, criar "um grande coletivo de singularidades que se descobre quando desconstruímos o senso comum" (AIRES, 2013, p.87). Segundo Tomas Tadeu da Silva: "mais do que um desvio da norma, a diferença é um movimento sem lei" (SILVA, 2002, p.66), que não tem nada a ver com o "diferente". O mesmo autor nos fala de [há] dois apontamentos sobre esta "diferença", âmbito do caráter de ilegalidade e das tentativas de legalização de certas práticas. O primeiro é que "a diferença não pede tolerância, respeito ou boa-vontade. A diferença, desrespeitosamente, simplesmente difere" (SILVA, 2002, p.66), ou seja, em sua condição de diferença os graffitis não estão a pedir espaço, "inclusão" ou aclamar uma identidade, eles estão a produzir diferença, invenção, e a nos fazer buscar o que se passa entre nós e eles, a compor com eles de modo a produzir um outro, que já não é mais nós ou ele, mas algo novo. O segundo diz que "mais que um desvio da norma, a diferença é um movimento sem lei" (SILVA, 2002, p.66), esses termos dão a dimensão do quanto ser "ilegal" é o que move muitas das inscrições urbanas, não apenas uma ilegalidade jurídica, mas uma busca pela liberação, ou libertação, de qualquer normatização que venha de uma suposta lei urbana que queira impor-se.

Por que desviar-se de uma norma? Porque há o desejo pela busca de uma abertura a múltiplas conexões, esta não obedece a um centro e encontra no desvio a força para produzir multiplicidade e agir como agente desestabilizador dos modos de habitar a cidade que não produzem "diferença". Para Suely Rolnik, "todas as entradas são boas desde que as saídas sejam múltiplas" (ROLNIK, 1989, p.66), essa abertura não segue o rumo das identidades que diz o que "é" algo, para ocupar-se com o que fazer com este algo, produzir diferença, fazer conexões, composições com a multiplicidade.

Problematizando os graffitis como práticas estéticas que envolvem a coletividade na produção de diferença, pergunta-se: como eles nos educam de modo informal? Como inventam nosso cotidiano? Quando potencializam a produção de novos modos de subjetivação? 
Pensamos as experiências com graffitis a partir do conceito de "potência" (NIETZSCHE, 1983, 2002, 2005), acompanhando o modo como elas ocorrem quando favorecem graus de potência, são movimentos de criação que resistem a um poder estagnante, um poder que define e serializa as subjetividades. Esse conceito de potência trata de uma busca pelo distanciamento da dicotomia "bom e mau". Vontade de potência é precisamente vontade de vida, sua condição fundamental. Capacidade de agir no conjunto de forças, capacidade de ser, de construir ou destruir, movimentar, promover composições. O que está em jogo é nossa capacidade de criar movimento na vida, para além de julgamentos morais. Em seu livro "Genealogia da moral", Nietzsche (2002) descreve o momento da consolidação do conceito de bom e mau e como estes são limitadores quando impostos/aceitos como verdades, pois são modos de ser baseados numa moral, numa conduta dominante que não pode ser considerada única ou suprema. A vontade de potência e a desconstrução andam juntas, pois não aceitam conservadorismos, trata-se da superação de si, da força que permite construir realidade, agir sobre ela, e não apenas aceitá-la como estabelecida.

Nietzsche (2002) tratou justamente sobre o confrontar o estabelecido, as verdades metafísicas, e levar a encontrar na vontade de potência uma processualidade capaz de geração e manutenção da vida, uma vontade que não é saciável, mas que está sempre em busca de mais. "É como se fosse uma vontade do organismo em que todo o corpo quer viver, é um aspecto primitivo onde não se pode escolher, que se manifesta quando encontra obstáculos e resistências" (LIMA, 2006, p.10). Para além de bem ou mal, justo ou injusto, o que está em jogo é este impulso que movimenta a criação.

Investigamos os graffitis tentando enxergar além da venda moral e seus filtros dicotômicos de certo e errado, do "bem comum" que, segundo Nietzsche (1983), no "comum" perde seu valor, pois aqui se trata de se estar de acordo com muitas pessoas. O problema disso é justamente nos aprisionarmos nos modelos e, nesse aprisionamento permitirmos que determinado poder, na forma de Estado ou outra personificação do poder, não nos deixe criar outras formas de viver, não nos permita viver nossa potência.

Destacar os conceitos de bom e mau em sua dicotomia resulta como uma linha de duas pontas, uma relação binária que abre um "meio", um lugar para pensar os graffitis em condição de existência, de devir, elemento potencializador na malha urbana da qual eles participam e que 
podem imprimir velocidade a vida. Então, ser um bom ou um mau graffiti não está em questão, não se busca julgamentos estéticos ou morais, importa é "quando" ele potencializa viver e produzir diferença, quando ele participa de uma produção de saberes que não obedece a um sistema educacional fechado e formal. Daí saberemos quando então ele propõe um encontro ativo, potente, sendo uma questão de contingência, de conveniência, de funcionamento.

Segundo Garcia (2005), "criou-se um discurso de que o saber veiculado pela educação formal é crítico, por ser racional, científico, por ter referências e ser pautado no conhecimento científico" (GARCIA, 2005, p.20), permitindo, a partir deste discurso, negar os saberes não sistematizados. O envolver-se com os graffitis permite uma aposta: há uma educação que ocorre para além dos espaços formais, rompendo com a crença de que apenas os conhecimentos sistematizados em currículos escolares, àqueles que frequentam salas de aulas, são capazes de oferecer uma formação "séria" e empreendedora.

Segundo Cynthia Farina (2008), podemos dizer que educação formal está contida na complexa configuração de formas de funcionamento do subjetivo, no processo de formação de subjetividade. Esse processo "dá-se em uma multiplicidade de espaços que atravessam uns aos outros. Nesse sentido, a formação inclui a educação formal, mas é maior e menor que esta, ao mesmo tempo" (FARINA, 2008, p.130).

Neste artigo compartilhamos experiências vivenciadas justamente nestes outros espaços que se estendem para além de uma educação formal, espaços em que a educação se dá de maneira mais difusa e espontânea, e que, por isso ocupa uma "educação informal", conforme Garcia (2005), espaços não sistematizados, sem uma definição e legitimação prévia de conteúdos e que, para Almerindo Afonso, "abrange todas as possibilidades educativas no decurso da vida do indivíduo, constituindo um processo permanente e não organizado" (AFONSO, 1989, p.78). Trata-se de experiência solta, imaginativa, sem professor e sem aluno, sem compromissos acadêmicos. A vida dando "lições", lições da vida que percorrem a cidade.

Segundo Garcia e Rotta (2011):

Somos educados por processos informais, formais e não-formais de maneira misturada, de forma que as trocas que realizamos e que realizam conosco, juntamente com as escolhas que fazemos nesse processo permitem que nós nos formemos e que nos deem forma mutuamente. Não é uma coisa primeiro que a outra e nem uma melhor que a outra, como também não significa que são 
complementarias no sentido de que um ato está e existe para completar o que falta (ou) de outro (GARCIA; ROTTA, 2011, p.11).

Como objeto de estudo as experiências com os graffitis configuram-se como experiências estéticas no sentido que nos diz Farina (2009), "uma experiência que altera as formas de ver e de dizer de um território de existência. E que, por isso, pode alterar suas formas de entender o que lhe acontece" (FARINA, 2009, p.137). Podemos pensar que essa alteração e entendimento contribuem para um processo que pode capacitar o sujeito a agir sobre este campo de forças tornando-o criador de um território existencial, dentre os múltiplos mundos que se entrecruzam na relação de si com o outro. Ao invés de habitar o mundo, um mundo "comum" a todos, resultado de processos totalizantes e padronizadores, permite-se ao homem-animal "ter" um mundo, um território, e não se apropriar de um sem construí-lo.

A educação estética tomada em sua dimensão pedagógica, ou seja, uma educação perceptiva informal que produz saberes, lança a experiência com os graffitis para o âmbito da arte. Ao falar sobre práticas estéticas, sobre a dimensão pedagógica da arte, Cynthia Farina (2008, p.4-5) diz: “[...] as práticas estéticas atuais parecem tratar-se como dispositivos de desnaturalização, como lentes de aumento sobre os modos de vida dos sujeitos [...]. Existe uma vontade sua de lidar e interferir na percepção, no conhecimento e nos modos de vida dos sujeitos".

Dispostos pelas ruas, muros e paredes da cidade, os graffitis podem produzir saberes de uma ordem que apela à liberdade e a possibilidade de invenção, cuja capacidade de imprevisibilidade aumenta a potência de criar outros modos de ser e viver cotidianamente, de "educar-se". Nestes caminhos trilhados nos é permitido explorar as múltiplas dimensões de um "aprender" como nos fala Sílvio Gallo (2012), algo para além da tradição ocidental em que "a educação tem sido pensada em matriz platônica, que afirma o aprender como recognição" (GALLO, 2012, p.1). Aprender não estaria assentado na emissão de signos (ensinar), mas no encontrar-se com estes signos. Nesse sentido, a possibilidade de um aprendizado estaria mais relacionada ao tornar-se sensível a este universo de signos. Entendemos por tornar-se sensível a evocação de uma sensibilidade possível, quando discutimos e atuamos na formação da percepção, "pois é a partir do que somos capazes ou não de perceber que produzimos conhecimento sobre nós mesmos e sobre o real" (FARINA, 2010, p. 3). Gallo (2012) chama 
atenção ainda para a impossibilidade de se aprender especificamente o que se ensina, de uma transmissão de signos, mas que, por outro lado, "qualquer relação, com pessoas ou com coisas, possui o potencial de mobilizar em nós um aprendizado, ainda que ele seja obscuro, isso é, algo de que não temos consciência durante o processo" (GALLO, 2012, p.3).

Com os graffitis podemos pensar nesse processo de aprendizado. E a ideia de cartografar tais processos vem com o desejo de dar a ver as transformações ocorrendo na subjetividade, junto aos aprendizados que vamos colecionando. Mobiliza-se um modo de aprender quando um graffiti se mostra capaz de liberar forças que configuram, desconfiguram e reconfiguram um território. Segundo Gallo, "não há métodos para aprender, não há como planejar o aprendizado" (2012, p.5), mas podemos colocar no processo de aprender não só com sensibilidade aos signos, mas também, "emitindo signos sem que tenhamos controle em relação ao que será feito com eles, por aqueles que os encontrarem" (GALLO, 2012, p.9) e "atentos ao processo, mais do que ao produto" (GALLO, 2012. p.10).

Diante desse modo de aprender sem um planejamento prévio seguimos passeando pela cidade, sempre sensíveis aos seus signos e na perspectiva de uma construção de muitas outras cidades por vir. Procuramos trabalhar com a ideia da cidade como um corpo em mutação. Com ele, outros corpos se misturam, corpos que compõem juntos, que formam juntos outros corpos a partir da experiência, corpos humanos e não-humanos. Não se trata apenas do corpo empírico, este viciado em seu movimento e sua forma, mas de um corpo de afeto, que afeta e é afetado, o "corpo espectral" como nos diz José Gil (2004):

[...] não se confunda com a presença, esbatida ou informe, ou o quer que seja, do corpo próprio. Pelo contrário, o corpo espectral é suscetível de múltiplas quase-formas: corresponde aos investimentos afetivos da linguagem que não aparecem no corpo físico visível a que se imprimiu a desfasagem original [...]. Não são formas, mas formas de forças, quer dizer dos investimentos inconscientes que compõem no corpo espectral (GIL, 2004, p.22).

O autor ainda nos fala de quando "os corpos se abrem" permitindo o contágio, permitindo que o corpo espectral se dissolva nas forças que se conectam com as forças do outro. Foi buscando compartilhar a experiência deste contágio, dos encontros com a cidade e as forças que nela circulam, atraem e repelem os corpos, que nos aventuramos a escrever sobre os 
graffitis. Aos poucos, fomos entendendo que precisamos de cidades como corpos em abertura, que não estejam apenas planejadas para a velocidade, levando consigo apenas roteiros préestabelecidos e lembranças enclausuradas em lojas de souvenires. Precisamos de cidades que, em algum gueto, algum canto escondido, alguma fresta se abra; construindo a cidade com a multiplicidade de outros mundos, "para permitir que se sinta o corpo da cidade em uma relação que não a da indiferença e da impessoalidade do passante em direção à sua prisão domiciliar" (COSTA; MIZOGUCHI; FONSECA, 2004, p.188). Dar passagem a um devir que esteja conectado e atento à lógica capitalística de produção de subjetividade, mas, para com ela sermos capazes de produzir outros saberes, outros modos de viver.

Na experiência com um graffiti o corpo físico abre-se para a ação, não opera de longe, o distanciamento é substituído por puro envolvimento. Segundo José Gil

[...] abrir o corpo é abrir o espaço de agenciamento de fluxos de intensidades, para que estes fluam segundo as vias mais adequadas. Agenciar é tecer, cerzir, atar, anexar, conectar, forjar os dispositivos apropriados à intensificação das forças [...] das consistências a osmose para que esta não se transforme numa sopa psicótica (GIL, 2004, p.27).

As pinturas não são feitas apenas com a mão, pois se percebe o envolvimento do corpo, seja na produção de um traço particular, no gesto, ou na escalada de um "pico" mais alto, no perigo. "Pico" é um local, um ponto de encontro, um bom local para fazer uma inscrição urbana, de boa visibilidade e desafiador. Não precisa ser necessariamente no alto, mas um local desejado, valioso.

É entre corpos humanos e a cidade que podem ocorrer agenciamentos. A cidade com seus prédios, suas ruas e asfalto, expelindo todo resto que não Ihe interessa para as periferias. Centro de consumo, de entretenimento, de produção seriada, funciona com macropolíticas que interessam ao tempo cronológico da pressa. Seus corredores de veículos estrangulam as habitações empilhadas, que crescem em sentido vertical, a "transformação do corpo da cidade em uma série de espaços fechados a partir de estratégias homogeneizantes e segmentadoras, que se ligam através de uma rede de deslocamentos e comunicações ultrarrápida, toma conta do espaço urbano" (COSTA; MIZOGUCHI, FONSECA, 2004, p.178). Em meio a esta realidade caberá inventar formas de resistir a esse tempo, de procurar outro tipo de experiência com um 
tempo, ou com a ausência dele, ver as horas num relógio sem ponteiros ou amolecido como nas pinturas de Salvador Dalí.

Dois momentos se produzem na experiência com um graffiti: a do artista, cuja execução pode variar de minutos ou de horas; a de um passante, experiência que ocorre nas mesmas condições de tempo. Porém, em ambos os casos se cria uma relação com um outro tempo, o tempo da "duração", transcendendo-se o tempo homogêneo da cidade, aquele aprisionado pela cronologia em sua ordem linear numérica. Da experiência efêmera com o muro pichado, que logo será repintado, marcas desafiam a efemeridade de uma inscrição urbana. Marcas, no sentido conceituado por Suely Rolnik, são "estados inéditos que se produzem em nosso corpo, a partir das composições que vamos vivendo" (ROLNIK, 1993, p.3), quando nossa forma atual é desestabilizada e forçada a produzir um novo corpo, a nos tornarmos outro. Outra espécie de memória, uma textura que, num plano invisível, "vai se fazendo dos fluxos que constituem nossa composição atual, conectando-se com outros fluxos, somando-se e esboçando outras composições" (ROLNIK, 1993, p.3) e que se produz pelo trabalho do pensamento, memória menos empírica e mais intensiva. Marcas se atualizam e agem na "duração". Capturam-se marcas produtoras de desejo, as quais são desafiadoras daquilo que, então, posto que "duram", seria passageiro.

Para Bergson (1988), o conceito de duração está relacionando com o tempo, tempo que é pura duração, onde não há mais uma relação de linearidade, sucessão ou cronologia. Tempo que não é da ordem da medida, do quantitativo, mas da ordem da sensação, do qualitativo. Um tempo em que "Não medimos já, pois, a duração, mas sentimo-la; de quantidade retorna ao estado de qualidade; a apreciação matemática do tempo decorrido já não se verifica; mas é substituída por um instinto confuso" (BERGSON, 1988, p.89) capaz ainda de cometer erros grosseiros e outras vezes proceder com extrema segurança. Duração-qualidade em que posso mergulhar quando, ao invés de contar os sons das badaladas do relógio, eu as sinto. O que seria várias unidades numéricas passa a ser percebida como um só bloco de sensação, que "dura". Como diz Bergson (1988) "as sensações produzidas por cada uma delas [os sons das badaladas do relógio], se fundiram [...] de maneira a adotar o conjunto de um aspecto próprio" (BERGSON, 1988, p.89). Na duração, esses blocos de sensações são criados e atualizados de modo contínuo e heterogêneo. 


\section{Graffiti}

Diversas formas expressivas de inscrições urbanas foram ganhando espaço e compondo a pesquisa de onde este artigo foi recortado. Dessas inscrições foi o graffiti que provocou as principais questões de investigação. Optamos por destacar estas manifestações por elas serem capazes de produzir interferências no vazamento das multiplicidades que constituem a nós e as coisas, uma produção policrômica que revela a cidade contemporânea em sua heterogeneidade e multiplicidade.

O graffiti já foi uma categoria mais geral capaz de representar uma série de inscrições urbanas, mas, aos poucos, foram surgindo outros grupos distintos como, principalmente, um certo tipo de graffiti e a pichação, também tag, trow-up, estêncil e lambe-lambe. Tomando a palavra graffiti em seu uso vemos que ela já significou uma série de manifestações desregradas, tratadas com espanto e perplexidade, quando subverteu a funcionalidade dos muros e paredes, muitas vezes de modo clandestino. Nas últimas décadas, o termo sofreu um processo de ressignificação e caracterização de uma identidade que vêm lhe reduzindo a uma técnica que passa a responder a um conjunto de regras e docilizações. Mesmo sendo parte da rua, e participando como elemento descartável na higienização e controle que sofre a cidade contemporânea, os graffitis continuam despertando curiosidade.

O termo graffiti vem especificando uma determinada técnica e um modo de pintar, uma forma que tem sido capaz, inclusive, de empacotá-lo e levá-lo para dentro de museus e galerias. Também, através de projetos sociais, como "Picasso não pichava" ${ }^{3}$, promovido pela Secretaria de Segurança Pública do Distrito Federal criado desde 1999, há promessas de tirar os jovens da pichação, ensinando-Ihes um graffiti que embeleza e enfeita a cidade e que pode ser usado de forma comercial, de modo "útil". Segundo Oliveira (2009) "Ele [o graffiti] se tornou antídoto contra a pichação" (OLIVEIRA, 2009, p.1). O graffiti tornou-se produto consumível. Muitos grafiteiros ascenderam de marginais a artistas, como o artista Jean-Michel Basquiat, americano, negro e de ascendência porto-riquenha, que começou seus trabalhos nas ruas e becos de Nova lorque na década de setenta, anonimamente usando o pseudônimo "SAMU", e depois foi

\footnotetext{
3 Projeto social "Picasso não pichava". Disponível em: http://www.ssp.df.gov.br/picasso-nao-pichava/. Acesso em 11 de jul. 2018.
}

Periódico Horizontes - USF - Itatiba, SP - Brasil - e020019 
convidado a expor em museus e galerias. Transformado em ícone pop, suas obras tornaram-se produtos e seus trabalhos ainda hoje atingem preços altos em leilões de arte. Mas o artista, que faleceu com apenas vinte e oito anos de idade, não chegou a aproveitar o sucesso de seu trabalho. O lucro desta iconificação - produção de um ícone, cristalização de um signo - não está apenas na venda do produto de seu trabalho, mas na produção de uma identidade, vendida a ávidos consumidores. Jorge Viesenteiner proferiu em sua palestra "O estatuto da ética em Deleuze", algo da ordem da iconificação que aconteceu com o hip-hop (movimento com o qual graffiti originalmente tem forte ligação). Diz:

[...] quando a cultura hip-hop é importada para o Brasil, ela se pretendia um movimento alternativo e desviante em relação aos agenciamentos de poder estabelecidos. Para o capital, uma ameaça externa. Cria seus próprios códigos e signos, linguagem e estilo de vida no interior dos guetos do país. Surge como suposta resistência montada contra a máquina de produção do Rosto. Imediatamente, porém, o capital se encarregou de sobrecodificar essa desviança que a cultura havia criado. É como se o capital dissesse: "Isso mesmo! Eu não valho nada! Critiquem-me pois eu sou um monstro". O que ocorre depois é que essa máquina abstrata confisca a cultura hip-hop e a vende sob a forma de um novo modo de vida (VIESENTEINER, 2006, p.6).

É visível que uma cultura graffiti tem sido celebrada ao ser utilizada por campanhas publicitárias e socioeducativas. A técnica graffiti invade galerias com artistas como Os Gêmeos e, nas ruas, passa a ser usada como combate a pichação, algo que antes era parte do universo do graffiti e que agora é tratado como o filho bastardo e combatido.

No contexto desta investigação, se buscou por uma forma de abordagem daquilo que inscrevem seus autores tentando "aprender" com os graffitis, mas sem querer explicações ou definições do que eles são, por um compartilhar das experiências que ocorreram a partir deles, com eles, fazendo um exercício de pensamento e abrindo para outros modos de ver, ouvir e sentir uma vida que nasce no urbano. Durante a investigação, a dificuldade de lidar com o graffiti como vandalismo foi vencida quando escapamos de julgamentos e conseguimos apreender forças para além das fronteiras de certo ou errado. Caminhadas, pedaladas - no dia e na madrugada - carregando gravador de sons, máquina fotográfica, bloco de anotações, ajudaram a capturar forças que circulam na experiência com os graffitis. Muitas vezes eles estão nos muros e paredes para embelezar, mas também podem incomodar e produzir pensamento, quase 
sempre estes foram os que mais nos interessaram.

Investigar processos de resistências com as manifestações de rua na cidade de Pelotas foi se tornando parte de nosso aprender. Envolvidos em processos de sedução, investimos numa produção capaz de fabricar um pensamento, ou seja, diminuir o enrijecimento de certas verdades que limitam o desejo, liberar a potência de viver, de que nos fala Nietzsche (1983). Ao caminharmos pela cidade percebemos que nem toda manifestação urbana se mostrava como um ato de resistência, no sentido em que escreve Gilles Deleuze (1999). Apesar de se diferirem de outras formas de produção, nem sempre criavam algo realmente novo, capaz de escapar de si, de realmente produzir diferença. Apenas porque supostamente eram produtos de grupos de artistas nascidos e vivendo na periferia, esses registros, por si só, nada garantiam como "resistência". Então, perguntamos: quando uma inscrição urbana como o graffiti, resiste? Quando esta produção de imagens é produção de pensamento, capaz de criar novos modos de ver, sentir, de pensar?

Tomemos a inscrição nas janelas seladas do então abandonado prédio em ruínas da antiga cervejaria Brahma, em Pelotas, assinada pelo grafiteiro Asnoum. Um trabalho não autorizado, mas durante o qual talvez o artista não tenha sido incomodado, já que o prédio estava abandonado. A partir da sua intervenção, as janelas do prédio tornaram-se janelas de um grande aquário de peixes dentuços, desenhados com um traço caricato capaz de imprimir humor à imagem sisuda deste imponente prédio em ruínas. O prédio situa-se em uma das principais vias da região do Porto, local de passagem de vários estudantes da escola básica - há duas escolas há menos de 500 metros dali - local de circulação de uma das linhas de transporte público da cidade e próximo a alguns prédios utilizados pela Universidade Federal de Pelotas (UFPel), adquiridos na última década, como o Instituto de Ciências Humanas (ICH), o Centro de Artes (CA) e a Faculdade de Educação (FaE).

Segundo Eduardo Rocha (2010), o lugar desola e impõe medo aos seus vizinhos, por servir de abrigo para delinquentes e dependentes de drogas e por seu constante processo de depredação, saqueamento de suas grades, portas, janelas, telhas, madeiramento do assoalho, entre outros itens. Mesmo que não reste quase nada de sua antiga composição há, ao mesmo tempo, tudo, pois "as ruínas conservam seu poder evocador e simbólico de reconstituição de passado e de imaginação. Lugares abandonados estão libertados de um sentido de intenção 
imediata, é pura experimentação" (ROCHA, 2010, p.123). Um terreno de ocupações efêmeras.

O prédio foi tomado por várias inscrições em seu exterior e interior, tornando-se um grande laboratório de desenhistas que agem sobre essas superfícies, re-significando, ora com humor, com desenhos carismáticos, ora acentuando o tom aterrorizador. O prédio abandonado torna-se espaço para o "fora de controle", parte de uma cidade abandonada que segundo Kevin Lynch (apud Rocha, 2010), é um lugar de terror e degeneração, uma sedutora mescla de liberdade e perigo. Uma exposição a céu aberto que escapa de curadorias, a não ser uma seleção de outra ordem, que pode se suceder entre os próprios grafiteiros, na composição deste corpo inscritor, um corpo coletivo. Inscrição sob inscrição a que se chama atropelo ${ }^{4}$.

Logo o prédio está tão tomado que a disputa por um canto se torna mais acirrada, alguns passam a se arriscar nos pontos mais altos, tomando galerias já em estado mais avançado de deterioração. Coração mais acelerado, maior nível de adrenalina, arriscam-se por seguir sua vontade de inscrever, de tomar o prédio, de misturar-se a ele deixando seu traço, seu personagem, seu $\operatorname{tag}^{5}$ marcado nele; de abrir seu corpo para misturar-se ao corpo da cidade. Ocupação coletiva. Desocupados que se ocupam com algo não esperado, não prescrevido por um regime de utilidade que se instaura na sociedade contemporânea. Não é um emprego, mas uma ação que não serve a um poder, pelo contrário resiste, torna-se vontade de potência, vontade de ser o que se é. Segundo Rocha (2010), há nesta antiga fábrica, e nos espaços de abandono, "um desejo de plenitude e de medo de destruição, ambos ao mesmo tempo" (ROCHA, 2010, p.148).

Não há como sistematizar tais saberes, pois se trata de uma força que sempre escapa de sistematizações categoriais. Aprender com eles implica nos permitirmos capturar por um instante, aceitar a instabilidade e, a partir daí, produzir outros corpos, formas de forças investidas no corpo, corpo espectral quase-forma de Gil. Trata-se aqui de pensar o corpo não como uma representação identitária, mas como uma multiplicidade. Para Deleuze e Guattari (1997), corpo é multiplicidade, processualidade constante "um corpo não se reduz a um organismo, assim

\footnotetext{
${ }^{4}$ Atropelo é quando um inscritor urbano pinta em cima da inscrição de um outro. Às vezes por achar que está fazendo uma modalidade acima, como um graffiti, sob um tag ou um pixo que considera mais simples, ou por uma guerra deflagrada entre dois grupos que passam a atropelar um o trabalho do outro.

${ }^{5}$ Tag é uma espécie de assinatura de um inscritor urbano ou grupo (crew). As letras costumam ser distorcidas favorecendo um determinado traço que diferencia a assinatura das demais.
} 
como o espírito de um corpo tampouco se reduz à alma de um organismo" (DELEUZE; GUATTARI, 1997, p.32). Ou ainda, como nos diz Spinoza (2014), o corpo como capacidade de afetar e ser afetado, mas que não se sabe antecipadamente de que afetos se é capaz. O poder de afeto deste corpo é justamente sua potência, aquilo que ele pode.

Cidade como superfície de inscrição e intervenção, ações que parecem ser anárquicas, constituidoras de um design anárquico do urbano, que se insere sobre seus espaços e o modificam. Ações que permitem outros mapeamentos, para além da ação reguladora, utilitária, dos aparelhos de Estado.

O cartografar movimentos de desterritorialização a partir de sujeitos inscritores urbanos que afirmam suas diferenças nos espaços da cidade com suas marcas, a constituição de territórios existenciais, a construção de novas formas de se escapar das armadilhas de uma forma clichê, são fatores que provocam percepções mudando a relação com a cidade. Não mais suja, pichada ou poluída, mas como um palimpsesto formado por reverberações, sobreposição de camadas, marcas de gritos que resistem a uma estagnação.

As experiências com os graffitis, feito um vetor de saída, constroem territórios, pois "não há território sem um vetor de saída do território, e não há saída do território, ou seja, desterritorialização, sem, ao mesmo tempo, um esforço para se reterritorializar em outra parte" (DELEUZE, 1988, p.4). Outra parte que constrói outra cidade, mais espontânea, aberta a surpresas e ao inesperado, aos desejos incontroláveis que liberam a vontade de potência, a vontade de fazer, vontade de viver. Uma restauração da "cidade subjetiva" que, segundo Guattari (1992), é capaz de engajar os níveis mais singulares, tanto da pessoa quanto do coletivo.

Andar pela cidade permite olhar a distribuição geográfica de sua malha urbana, nesse contexto os graffitis se apresentam sob formas distintas. O modo como alguns "brotam" muitas vezes em maior quantidade nas zonas periféricas mais abandonadas e, por consequência, menos vigiadas, difere de como são apresentadas no centro da cidade ou nos bairros mais nobres.

Houve uma época em que a palavra CRIME, com letras de diversos tamanhos, estampada sobre placas de trânsito, paredes e portões de garagem, e em distintas regiões, tomou conta da cidade de Pelotas, tudo em um período inferior a seis meses. O curioso é que eram graffitis que não seguiam um padrão caligráfico, como se executadas por mais de uma pessoa, o que parece se confirmar quando se considera a quantidade de pichos num espaço tão curto de tempo. Isso 
fez indagar: até que ponto a ilegalidade é determinante para que um graffiti se manifeste como forma de resistência? Para além da ilegalidade, quando os artistas urbanos operam dentro de uma legalidade, há ainda uma dimensão criadora?

No centro da cidade, como um ruído, eles surgem em rabiscos, marcas que estampam pequenos objetos públicos, em placas de trânsito, hidrantes, na forma de stickers, espécie de selos em papel colados aqui ou ali, que parecem criar um mapa ou deixar um recado àquele que percebe sua presença, que se dispõe a entrar no jogo das decifrações enigmáticas.

Muros se erguem ao redor das casas, somadas a cada vez mais frequentes camadas de arame farpado e cercas elétricas. Muros, paredes e pisos das cidades são parte da pele que reveste um corpo coletivo, são seus limites físicos, contenções ou proteção de um corpo. Sugere Ferreira (2005) pensar também que o corpo pode crescer da periferia para o centro, "partindo da pele, como contrapartida de suas relações com um meio ambiente" (FERREIRA, 2005, p.20).

Nos tapumes que delimitam um antigo casarão em processo de restauração em Pelotas, há o trabalho de um grafiteiro conhecido por suas figuras emblemáticas facilmente percebidas em outros pontos da cidade - um rosto sob uma máscara de madeira e um nariz de palhaço. Desenho que ano a ano se altera, recebendo novas estilizações, mas mantendo-se visualmente as suas reproduções anteriores. Este rosto algumas vezes é seguido de frases de protesto, como "educação é fundamental", e "em época de eleição, todo mundo é tratado como cidadão".

O fato de tratar-se de uma cara-de-pau com um nariz de palhaço seguido da palavra "ovop", inversão da palavra "povo", já revela certa intencionalidade. Em um destes trabalhos há a frase "me empresta um sorriso", palavras que surpreendem quando chegam num destes momentos frenéticos que a vida contemporânea impõe. O graffiti pergunta: será que temos tempo para um sorriso? Será que só um cartão de crédito "mastercard" é que capaz de pagar por um, como dizem as peças publicitárias? Há como "emprestar um sorriso", há como produzilo através da surpresa? Mas este será devolvido? Por quem? Pelo muro, pelo outro? O que se passou ali foi um lapso de uma fuga, uma fuga da rotina, uma pedra que desvia do caminho, ou até mesmo faz o caminho por instantes desaparecer.

Deleuze e Guattari (1997) falam-nos de uma "máquina abstrata sobrecodificadora" que atua de maneira homogeneizante produzindo modelos os quais, agenciando-se a outras máquinas, introduzem rostos, num processo que os autores chamam de rostidade, ou seja, uma 
operação a partir de relações binárias e dicotômicas. Segundo Deleuze e Guattari (1997), uma máquina abstrata não funciona para representar, "mas constrói um real por vir, um novo tipo de realidade" (DELEUZE; GUATTARI, 1997, p.100). Existem diferentes tipos de máquinas abstratas "aquelas relacionadas com o plano de consistência atuando positivamente, não dominam e nem esgotam o conjunto de operações que constituem os estratos" (MAGNAVITA, 2004, p.8) e constata-se também a presença de máquinas abstratas servindo de manutenção e atualização de um "estrato", de uma determinada forma de poder, como o Estado. Proliferam as leis que tentam regular o que pode e o que não pode ser dito, feito, manifestado, pintado. Segundo a constituição federal é "livre a manifestação do pensamento, sendo vedado o anonimato" (BRASIL, 1988, art. $5^{\circ}$ ), uma vez identificado o indivíduo pode ser penalizado quando ultrapassa os limites do "livre" mencionado.

Não são permitidos anonimatos. Somos digitalizados desde o nascimento, memorizados em bancos de dados capazes de identificar nossos rastros, da marca do dedo polegar já aprimoramos para o reconhecimento de face, da íris do globo ocular. Conforme Heliana Conde (2010), em entrevista a Carlos Batista, as leis nos dizem o que é proibido e os dispositivos disciplinares o que é permitido, assim, um comportamento é esperado, uma conduta adequada é manifesta, as forças tendem as nos envergar a uma configuração dominante.

Nosso cotidiano cada vez mais se mune de câmeras de segurança espalhadas por mais pontos da cidade. Somos observados de cima, através de satélites que orbitam o globo terrestre. O sistema de posicionamento global (GPS) fornece a localização exata de tudo e de todos, da mesma forma as retém para que depois você possa ser identificado. O usuário Malte Spitz chamou a atenção para a "Norma de Retenção de Dados" (informação verbal) ${ }^{6}$, aprovada pela Comissão da União Europeia no verão de 2006, que obriga as companhias telefônicas e provedores de internet a guardar uma enorme variedade de informações sobre os usuários, o equivalente à de seis meses a dois anos de histórico de dados. Spitz conseguiu na justiça o direito a receber uma cópia das 35.830 linhas de código - um detalhado relatório, quase minuto a minuto, de meio ano de sua vida, com o qual demonstrou que era possível determinar cada deslocamento nesse período, para quais pessoas ligou, quais são suas conexões sociais. Imagine

\footnotetext{
${ }^{6}$ Palestra apresentada em uma conferência oficial da TED (organização sem fins lucrativos, dedicada à difusão de ideias) em junho de 2012. Vídeo e transcrição disponíveis em: http://on.ted.com/Spitz. Acesso em: 17 dez. 2013.
}

Periódico Horizontes - USF - Itatiba, SP - Brasil - e020019 
poder identificar os líderes de qualquer manifestação, antecipar a formação de agrupamentos, antecipar jogadas como mestre do xadrez?

Precisamos considerar que, "se novas tecnologias [de controle] estão emergindo, novas experimentações de liberdade que possam produzir resistências, uma resistência ativa, também são necessárias" (CONDE, 2011, vídeo-entrevista). Assim, as mutações de uma máquina de controle nos fazem perguntar como resistir, ou perguntar sobre quais outras formas de resistir estão sendo - ou precisam ser - inventadas.

Inscrições urbanas já produziram alguma vez "formas de resistência", como durante os protestos de maio de 68 ou nos trens e metrôs da cidade de Nova lorque da década de 70. Descreve Jean Baudrillard (1996):

[...] unicamente os grafites e os cartazes de Maio de 68 na França se desenvolveram de uma outra forma atacando o próprio suporte, conduzindo os muros a uma mobilidade selvagem, a uma instantaneidade da inscrição que equivalia a aboli-los. As inscrições e os afrescos de Nanterre exemplificavam muito bem essa reversão do muro como significante da quadrilhagem terrorista e funcional do espaço, através de uma ação antimídia (BAUDRILLARD, 1996, p.103).

Apesar de todo monitoramento tecnológico, os graffitis continuam a proliferar nas paredes e muros das cidades, seja de modo clandestino, ou, como está se tornando característico em nossa época, incentivado pelas esferas pública e privada como, por exemplo, no concurso "Call Parade"7 de uma empresa de telefonia, a qual convidou artistas à enviar propostas e cujas selecionadas foram pintadas em cem orelhões da cidade de São Paulo, para "transformar nossos orelhões em obras de arte". Ou alguns trabalhos do grafiteiro Eduardo Kobra, como o painel de 50 metros com um retrato estilizado e colorido do arquiteto Oscar Niemeyer, encomendado pela prefeitura para comemorar os 459 anos da cidade de São Paulo, ou os murais pintados, um no Centro Cultural Puertas de Castilla, na cidade de Murcia, Espanha, e outro no hospital Queen Elizabeth, na cidade de Blantyre, Malawi, ambos em 2017.

As transformações que o corpo dia a dia vai tendo de suportar, composições que se fazem no invisível, a partir de conexões e soma de fluxos, constrói uma memória que é feita de fatos e

\footnotetext{
${ }^{7}$ Concurso promovido pela empresa "Vivo Telefonia". Disponível em: http://callparade.com.br. Acesso em: 18 mar. 2013.
}

Periódico Horizontes - USF - Itatiba, SP - Brasil - e020019 
de marcas, se fazem em nosso corpo e podem ser eventualmente reativadas, "cada marca tem a potencialidade de voltar a reverberar quando atrai e é atraída por ambientes onde encontra ressonância" (ROLNIK, 1993, p.2), por isso o aprendizado com a cidade, em particular com os graffitis, não se encerra em um momento, mas nas constantes situações em que reativamos estas marcas, esses outros modos de vivenciar a cidade. Como se as inscrições funcionassem como dispositivos capazes de desestruturar a cidade cada vez que a organizamos, desmontando e embaralhando as peças, nos permitindo montá-la de outra forma, uma nova cidade a cada reverberação.

Nos vários espaços que ocupamos, determinados processos de subjetivação passam a agir sobre os corpos, fazendo surgir outros "eus", que se confrontam e, nestes confrontos, alguns padecem. Segundo Mansano (2009), em seu artigo sobre sujeito, subjetividade e modos de subjetivação, trata-se de trocas coletivas. Em cada sujeito que "acolhe os componentes de subjetivação em circulação, também os emite" (MANSANO, 2009, p.111). Talvez a tensão em resistir às diversas subjetividades que nos são impostas seja a causa de tantos fármacos e especulações psicanalíticas que ingressam conosco no século XXI.

A paisagem das cidades na atualidade responde a geografia de determinadas forças de produção de uma subjetividade baseada no consumo. Proliferam-se os centros de consumo como os shoppings centers, os aparatos publicitários e uma parafernália que vende, antes de produtos, estilos de vida. Por um lado, como forma de criação, de resistência, no sentido que nos fala Gilles Deleuze (1999), elas podem atuar resistindo às subjetividades estabelecidas. Resistir, nesse sentido, é assumir a postura de quem se opõe à ordem das coisas, rejeitando ao mesmo tempo o risco de subverter essa ordem. Por outro lado, perguntamos até que ponto as inscrições urbanas, ou determinadas inscrições urbanas, já não foram capturadas por uma forma de subjetivação que surge com a instalação do capitalismo cultural na segunda metade dos anos 70, tendo a figura do grafiteiro, do pichador, do inscritor urbano como um sujeito já regulamentado, que opera dentro de um campo sistematizado, e que já não surpreende.

Alguns graffitis, os que nos interessam, traçam movimentos de desterritorialização e desestratificação capazes de acender uma faísca que, numa sequência rizomática, promove outras fugas, possibilitando a construção de outros territórios para além dos instituídos, de outros modos de ser. 
O elemento surpresa instiga a querer mais aqueles encontros inesperados e inusitados. Chegar a uma determinada rua, a uma esquina, e se perceber arrancado de uma rotina, uma rotina de serventias. Fadiga de um dia estressante. Distração que busca um "nada" no horizonte. Ser tirado daquilo que vivemos como massacrante quanto ao que esvazia e que diminui a potência da vida, como se estivéssemos numa terra tomada por zumbis. Permitir-se aprender com a cidade, buscar as cidades múltiplas que habitam o cotidiano, erguer outras dentre as “Cidades Invisíveis" de Ítalo Calvino (2003). Ter os graffitis como agentes da subversão, da ação não pautada, capaz de criar outros caminhos, provocar outras sensações no corpo da cidade em conjunto com o corpo do cidadão. Promover misturas, novos pigmentos.

Nas ruas há uma vida impressionante, há força e risco em muitas investidas, quando se tomam terrenos baldios, quando um pedaço de parede é marcado com spray, realizando um desenho, uma escrita ou um outro tipo de interferência capaz de criar um ponto na malha. Não um ponto de começo ou fim, mas um ponto de atração, de interferência, capaz de gerar um vórtice. Um ponto não aguardado, não autorizado, que define uma outra malha para a cidade, transformando a paisagem urbana, criando outras paisagens, outros sujeitos, outras pedras, outros animais, outros elementos.

Quando um graffiti se converte em potência, escapando das mediocridades, dos modelos, das mesmices e dos clichês, ele é capaz de afetar o conjunto de forças que criam realidades. Energia desprendida em muitos dias de trabalho, com painéis que chegam a medir cinco metros quadrados, composição que não tem pressa para acabar, pois estabelecida outra relação com o tempo e com o espaço. Como se outra vontade de viver a vida ganhasse forma, um modo de resistir, de criar outros territórios existenciais. "Caras" se penduram no alto de prédios sem equipamentos de segurança, movidos por uma vontade de dar algo de si. Cada centímetro do corpo físico move-se diante de seus variados suportes. Não há uma tela plana com limites definidos, mas uma superfície com as mais variadas texturas, que participa da composição. Imperfeições superficiais aproveitadas, fendas reaproveitadas, estendidas, resignificadas.

Articular experiências com graffitis e conceitos da filosofia, funcionou como dispositivo de aprendizagem capaz de permitir lançar outros olhares sobre o real, atento aos modos de como ele se materializa, ou se liquefaz. Acreditamos que os devires se potencializam quando 
tomamos as ruas pelas caminhadas, "a caminhada afirma, lança suspeita, arrisca, transgride, respeita [...]" (CERTEAU, 1998, p.179), caminhadas pela cidade no sentido certeauniano, fazendo dos passos matéria-prima para as operações que colocam o cotidiano em movimento.

Buscamos favorecer uma extensão horizontal capaz de encontrar, de fato, inscrições como marcas, aquelas incisivas, gravadas na pele urbana e não apenas superficialmente "sobre" as paredes. Essa ideia de incisão está relacionada ao modo de permanência destas marcas, que vão além da matéria - tinta, carvão, terra - aplicada de modo efêmero no espaço, ou até da ausência de uma matéria que permaneça. Há inscrições que permanecem, pois transformam, criam.

Procuramos ouvir as marcas deixadas nos muros e paredes da cidade, inscrições urbanas capazes, muitas vezes, de transcorrer por espaços marginais, brotar como ervas daninhas, abalando as estruturas de um sistema que as buscam cooptar, ou abafar, da mesma forma que as combate, "rostificando-as". Muitos trabalhos de inscritores urbanos, sozinhos ou no coletivo, mostram que a cidade se torna um campo de atuação criador. Problematizar estes produtos e os processos criadores que os engendram favorece uma cartografia que faz deles sua fonte de produção, produção de subjetividades que tenta destacar a "diferença".

\section{Conclusão}

Através da cartografia traçamos um mapa, que não quer ter status de verdade, mas que nos permitiu trilhar caminhos para além das estradas já evidenciadas em outros mapas, em outros estratos. Mapeamos forças que nos levaram a outros caminhos possíveis, a outras linhas que por vezes nos desconfiguraram e nos fizeram mergulhar em incertezas, com as quais tínhamos que criar alguma linha de sustentação, ou seja, criar um corpo que, através deste processo de construção e desconstrução, nos permitisse aprender a lidar com este conjunto de forças, a nos tornarmos mais descolados, no sentido de um desprendimento ao conjunto de forças molares que insistem nos formar a cada dia.

Macro e micropolíticas coabitam este espaço de forças, entrecruzam e competem. Somos atravessados pelas macropolíticas, práticas organizadoras da cidade capazes, segundo Michel de Certeau (1998), de criar uma espécie de cegueira. Mas, se pode aprender com os graffitis que há como agir sobre estas macropolíticas, criando micropolíticas, favorecendo, ao invés de um 
cotidiano baseado em rotina e regularidades normativamente esperadas, um cotidiano baseado em movimento, que se constitui de rupturas, o caminho da "invenção do cotidiano" que nos diz Certeau (1998), trata-se de um modo possível.

Graffitis se compõem junto às forças cotidianas, é toda uma coletividade participando de uma invenção, ou de uma reprodução, não se sabe ao certo. O que um grafiteiro deixa registrado em um muro diz respeito a ele, a nós e a todos que habitam e constroem uma cidade. Há percussões e repercussões que nos unem como sonoridades que não vemos, mas que percebemos, basta andarmos pelas ruas.

Seguindo o intuito deste trabalho, acreditamos ter conseguido mapear algumas experiências, trazendo-as até aqui em seus processos de aprendizagem e de resistência no espaço urbano. Constituímos um mapa que problematiza os graffitis quanto a sua capacidade de educar segundo um princípio de informalidade, arte que colabora para uma educação estética potencializadora.

\section{Referências}

AFONSO, A. J. Sociologia da educação não-formal: reactualizar um objecto ou construir uma nova problemática? In: ESTEVES J., STOER, S. (Orgs.). A sociologia na escola: professores, educação e desenvolvimento. Porto: Afrontamento, 1992, p.83-96.

AIRES, A. Estratégias de renovação da telenovela: a produção de uma estética da diferença em Cordel Encantado. 2013. 166f. Dissertação (Mestrado em Comunicação e Práticas de Consumo) - Programa de Pós-graduação em Comunicação e Práticas de Consumo da Escola Superior de Comunicação e Marketing - ESPM/SP, São Paulo, 2013.

BAUDRILLARD, J. Kool killer ou a insurreição pelos signos. In: BAUDRILLARD, J. A troca simbólica e a morte. São Paulo: Loyola, 1996.

BERGSON, H. Ensaio sobre os dados imediatos da consciência. Trad. J. S. Gama. Lisboa: Edições 70, 1988.

BRASIL. Constituição (1988). Constituição da República Federativa do Brasil. Brasília, DF, Senado, 1998.

CALVINO, I. As cidades invisíveis. Trad. Diogo Mainardi. São Paulo: Biblioteca Folha, 2003.

CERTEAU, M. A invenção do cotidiano - artes de fazer. Trad. Ephraim F. Alves. 3. ed. Petrópolis, 
RJ: Vozes, 1998.

CONDE, H. Foucault e a sociedade disciplinar. [Entrevista cedida a] Carlos Batista. Vídeos de Carlos Batista. Bahia, mar/ abr. 2011. Disponível em: https://vimeo.com/15700255. Acesso em: 06 abr. 2020.

COSTA, L. A.; MIZOGUCHI, D.; FONSECA, T. G. Corporeidade: (inten)cidade dos corpos urbanos. In: FONSECA, T.; ENGELMAN, S. (Orgs.). Corpo, arte e clínica. Porto Alegre: Editora da UFRGS, 2004, p.171-190.

DELEUZE, G. O abecedário de Gilles Deleuze: transcrição integral do vídeo, para fins exclusivamente didáticos. Éditions Montparnasse: Paris, 1988.

DELEUZE, G. Conversações. Trad. Peter Pál Pelbart. São Paulo: Editora 34, 1992.

DELEUZE, G. O ato de criação. Trad. José M. Macedo. Folha de São Paulo, Caderno Mais!, 27 jun.1999.

DELEUZE, G; GUATTARI, F. Mil platôs: capitalismo e esquizofrenia, v. 5. São Paulo: Ed. 34, 1997.

FARINA, C. Arte e formação: uma cartografia da experiência estética atual. In: 31 a REUNIÃO ANUAL DA ANPED, 2008, Caxambu, Minas Gerais. Anais [...] 31a. Reunião anual da ANPED, Caxambu, 2008.

FARINA, C. Modulações do sensível: políticas da experiência estética atual. Revista de Estudios Transdisciplinarios, Caracas v.1, n.1, p.127-148, 2009.

FARINA, C. Políticas do sensível no corpo docente - arte e filosofia na formação continuada de professores. Revista Thema, Pelotas, n.7, p.01-13, 2010.

FERREIRA, P. O dentro e o fora. Revista Nada, Lisboa, n.5, p.18-25, 2005.

GALLO, S. As múltiplas dimensões do aprender... Congresso de Educação Básica: Aprendizagem e Currículo - COEB, 2012. Disponível em:

http://www.pmf.sc.gov.br/arquivos/arquivos/pdf/13_02_2012_10.54.50.a0ac3b8a140676ef8a e0dbf32e662762.pdf. Acesso em: 15 jul. 2018

GIL, J. Abrir o corpo. In: FONSECA, T.; ENGELMAN, S. (Orgs.). Corpo, arte e clínica. Porto Alegre: Editora da UFRGS, 2004, p.13-28.

GARCIA, V.A. Um sobrevoo: o conceito de educação não formal. In: FERNANDES, R. S.; PARK, M. B. (Orgs.). Educação não-formal: contextos, percursos e sujeitos. Campinas/Holambra: UNICAMP/CMU/Editora Setembro, 2005, p.19-43.

GARCIA, V.A.; ROTTA, D. Cartografias da educação não-formal. Revista de Ciências da Educação, n.25, p.53-69, 2011. 
GUATTARI, F. Caosmose: um novo paradigma estético. São Paulo: Ed. 34, 1992.

LIMA, G. Vontade de poder e o ideal ascético em Nietzsche. 2006. 50f. Monografia (Bacharelado em Filosofia) - Departamento de Filosofia, Universidade Católica do Salvador, Salvador, 2014.

MAGNAVITA, P. Diferente forma de pensar a cidade e o urbanismo - a história e a lógica da multiplicidade. In: VIII SEMINÁRIO - HISTÓRIA DA CIDADE E DO URBANISMO, 8, 2004, Niterói. Anais [...] Perspectivas contemporâneas da história da cidade e do urbanismo. Niterói: ANPUR, 2004. p.1-15.

MANSANO, S. R. V. Sujeito, subjetividade e modos de subjetivação na contemporaneidade. Revista de Psicologia da UNESP, v.8, n.2, 2009, p. 110-117.

NIETZSCHE, F. Obras incompletas. 3. ed. Trad. Rubens R. Torres Filho. São Paulo: Abril Cultural, 1983. (Coleção Os pensadores).

NIETZSCHE, F. Genealogia da moral: uma polêmica. Trad. Paulo César de Souza. São Paulo: Companhia das Letras, 2002.

NIETZSCHE, F. Além do bem e do mal: prelúdio a uma filosofia do futuro. Trad. Paulo César de Souza. São Paulo: Companhia das Letras, 2005.

OLIVEIRA, G. R. C. Pixação: arte e pedagogia como crime. 2009. 375f. Dissertação (Mestrado em Educação) - Programa de Pós-graduação em Educação da Faculdade de Educação, Universidade do Estado do Rio de Janeiro, Rio de Janeiro, 2009.

ORWELL, G. 1984. 29.ed. São Paulo: Ed. Companhia Editora Nacional, 2005.

ROCHA, E. Arquiteturas do abandono: ou uma cartografia nas fronteiras da arquitetura, da filosofia e da arte. 2010. 263f. Tese (Doutorado em Arquitetura) - Programa de Pós-graduação em Arquitetura da Universidade Federal do Rio Grande do Sul, Porto Alegre, 2010.

ROLNIK, S. Cartografia sentimental: transformações contemporâneas do desejo. São Paulo: Estação Liberdade, 1989.

ROLNIK, S. Pensamento, corpo e devir: uma perspectiva ético/estético/política no trabalho acadêmico. Cadernos de Subjetividade, São Paulo, v.1, n.2, p.241-251, set./fev.1993.

SILVA, T. T. Identidade e diferença: impertinências. Educação \& Sociedade, n.79. p.65-66, ago. 2002.

SPINOZA, B. Ética. Belo Horizonte: Autêntica Editora, 2014.

VIESENTEINER, J. L. O estatuto da ética em Deleuze. 2006. (Apresentação de Trabalho/Conferência ou palestra). Disponível em: https://pt.scribd.com/doc/16661632/Oestatuto-da-etica-em-Deleuze. Acesso em: 15 jul. 2018. 
Recebido em julho 2018.

Aprovado em janeiro 2020. 